\title{
Optimizing Software Team Performance with Cultural Differences
}

\author{
Greg S. Anderson \\ Brigham Young \\ University \\ greg.anderson@byu.edu
}

\author{
Mark J. Keith \\ Brigham Young \\ University \\ mark.keith@gmail.com
}

\author{
Conan C. Albrecht \\ Brigham Young \\ University \\ doconix@gmail.com
}

\author{
Alex N. Spruill \\ Brigham Young \\ University \\ alex.n.spruill@gmail.com
}

\author{
Clayton Pettit \\ Brigham Young \\ University \\ cpet13@gmail.com
}

\begin{abstract}
Software development is primarily a team task that requires a high degree of coordination among team members [1]. Prior research has indicated that the composition of team member traits such as personality and culture can influence the performance of software teams [2]. However, this line of research does not give practical guidance on how to build teams with personnel constraints. Some research has built teams by starting with personality [2]. However, cultural traitswhich are also known to influence team performancehave not been examined in the same manner. This research, therefore, builds upon this stream by: 1) examining the effects of Hofstede's [3] latest sixdimensional model of national culture [4], 2) segmenting potential software team members into distinct cultural clusters, and 3) testing the outcomes of teams built upon homogeneous versus heterogeneous cultural compositions over time. Our results indicate that-consistent with prior research-homogeneous team compositions are initially better for performance. However, this effect reverses over time, and heterogeneous team compositions are superior.
\end{abstract}

\section{Introduction}

The software development process has evolved over time but continues to rely heavily on the use of teams. Since success or failure hinges on a team's ability to collaborate to produce quality work [5] and given the high rates of software project failure [6], building successful teams is a critical task that has received considerable research attention.

For example, much research has focused on combining the right sets of knowledge and skills in a software team [7]. It is well-established that teams with diverse functional skills perform better than those with homogenous skillsets $[8,9]$. However, teams are not just a set of combined skills and experience. Teams are made up of people with unique cultures and personalities - all of which are known to impact team performance $[5,10$, $11]$.
Research has shown that people tend to align with those of similar cultural backgrounds [12-14]. Therefore, it is useful to understand how composing teams of similar versus diverse cultural backgrounds will affect team software performance [11]. However, prior research has produced mixed results concerning the desirability of team homogeneity versus heterogeneity [15]. Furthermore, it is apparent that the effects of team cultural composition change over time [16].

Therefore, the purpose of this research is to 1) better explain the effects of team cultural heterogeneity in the software development team context over time, and 2) provide a prescriptive approach to managers for team formation based on the results.

Recent research has made similar progress toward these goals by examining personality (as opposed to cultural) trait heterogeneity in software teams [2]. To complement prior work, we focus this study on cultural values, beliefs, and attitudes using Hofstede's sixdimensional model of national culture [4], and we compare it to the prior research in the discussion.

Understanding the role of culture is relevant, and even critical, to software teams because they are almost all increasingly being composed with multi-national members [17, 18]. Furthermore, information systems (IS) academic programs predominantly use teams for coursework and general learning [19], and they aspire to be composed of students from diverse cultural backgrounds.

In studying team cultural composition, we focus on two unique outcomes. As is typical of team research, we examine cultural variance on team performancewhich is of primary interest to every organization. Next, we examine individual team member learning - an outcome of great importance to the software development context because of the constant change taking place in technology, programming languages, and best practices.

We performed a laboratory experiment with 39 student software teams (total of 141 participants) who were assigned to groups of 3-4 members with either 1) homogeneous cultural compositions or 2) heterogeneous cultural compositions. Our results 
indicate that teams with homogenous cultures performed better initially. However, the effect reversed over time and as heterogeneous teams matured, performance improved.

\section{Literature and Theory}

In this section, we build our theoretical model. The core of the model is based on several meta-analytical theoretical reviews of the effects of team cultural personality compositions and their outcomes [15, 20]. Figure 1 is an adaptation of their findings. In general, the research findings on team cultural composition indicate that individual cultural values and beliefs determine the team cultural composition. The team's cultural composition is measured either or both as the mean scores across a selected set of cultural measures and the variance, or heterogeneity, of those measures across team members. Lastly, that team composition affects team performance, team processes, and individual self-perceptions of team members. To explain our use of this model, we begin by defining the individual culture values and beliefs model that we use as the basis of our measurement of team culture.

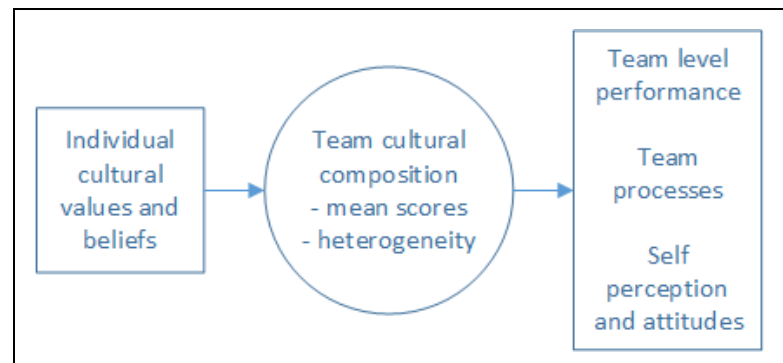

Figure 1. Team Culture Theory (adapted $[15,20])$

\subsection{National Culture: Six-Dimensional Model}

Although a number of models exist to represent national culture, Hofstede's model is perhaps the most cited and dominant model in the field. He defines culture as "the collective programming of the mind distinguishing the members of one group or category of people from others" [3, p. 5]. Based upon his extensive research using more than 117,000 questionnaires across 67 countries over a six-year period, he developed a cultural dimensions theory founded upon six dimensions describing the effects of a society's culture on member's values and how these values form behaviors. We describe these dimensions below based on Hofstede's relevant works [3, 21].

2.1.1. Power Distance Index. The Power Distance Index (PDI) dimension is "the extent to which the less powerful members of institutions and organizations within a country expect and accept that power is distributed unequally" [21, p. 98]. It is not the actual difference of power between members but instead the member perception of power distribution.

A high PDI score indicates that society members accept the unequal distribution of power and accept their role with little critique or criticism of authority. An example would be a worker's dependence upon a superior. Members accept a hierarchical order and have greater fears of disagreeing with superiors. They acknowledge the leader's status and do not question the authority to the point that one may need to go to the superior for a decision to be made.

A low PDI score indicates a sharing of power where members view themselves as equal to others. There is little dependence of the worker upon the manager and instead members feel they can freely communicate with superiors and even contradict them. Superiors delegate as much as possible and all are usually involved in the decision making.

2.1.2. Individualism vs. Collectivism. The Individualism versus Collectivism (IDV) dimension is "the degree to which individuals are integrated into groups" [21]. Individualism (represented with a high IDV score) is the society where individuals are expected to take care of themselves, their families, and friends. Priority is placed upon personal achievements, personal identity, and individual rights.

Collectivism (represented with a low IDV score) occurs when members tend to work and think as a group (strong team cohesion). Individuals are more likely to sacrifice their own gains for the greater good and, in exchange for loyalty, the group will defend a member's interests. There is a respect for tradition and changes take time since there is greater respect of age and wisdom. Members avoid giving public negative feedback and instead focus on maintaining harmony.

2.1.3. Uncertainty Avoidance Index. The Uncertainty Avoidance Index (UAI) dimension refers to a willingness to accept uncertainty and ambiguity. It is the degree to which society tries to cope with anxiety by minimizing uncertainty and being governed by rules, laws, and procedures.

Members in societies with a high UAI tend to be more emotional and are governed by rules. They like things to be clear and concise about expectations. There is a great deal of emphasis placed on planning, communication, and staying on schedule.

Those in a low UAI tend to be more realistic and more tolerant of change. They value differences and are encouraged to have few rules. Members are accepting of change and risk and usually have more of an informal 
business attitude.

Low uncertainty avoidance (i.e. "risk-seeking") has been demonstrated to be favorable for team performance in some contexts [22].

2.1.4. Masculinity vs Femininity. The Masculinity versus Femininity (MAS) dimension, also called "Quantity of Life versus Quality of Life" or "Tough versus Tender", is the distribution of emotional roles between the genders. It defines how society embraces the traditional male and female roles.

High MAS scores favor masculinity and are based upon cultures that value attributes such as competitiveness, heroism, assertiveness, materialism, ambition, and power. These are usually societies where the male and female roles and work are distinct. There is a greater emphasis placed on economy over environment. Money and achievement are important. There are large military defense budgets and less spent on charitable international aid.

In a society with low MAS score emphasis is placed more on relationships and quality of life. Men and women are treated equally with the attitude of "a woman can do anything a man can do". Powerful and successful women are admired and respected.

2.1.5. Long-Term vs. Short-Term Orientation. The Long term (pragmatic) versus Short term (normative) orientation (LTO) dimension was first called Confucian dynamism but it did not adequately reflect Asian perspectives on culture [21].

Short-term oriented societies show respect for traditions and avoid doing things that will cause another person to "lose face" or suffer disgrace. It emphasizes quick results with an absolute belief in good and evil along with fulfilling social obligations.

Long-term oriented societies focus on the importance of the future and are geared towards future rewards, perseverance, and thrift.

Cultures with a high LTO have employees with a strong work ethic, who show respect for differences and value social order and long-range goals. Those with a low LTO are more concerned with short-term results and quick gratification for their needs.

2.1.6. Indulgence vs. Restraint. The Indulgence versus Restraint dimension (IND) is the extent to which a member tries to control their desires and impulses. Societies with a high IVR encourage gratification (enjoying life and having fun). These societies focus on not taking life too seriously and being optimistic with a focus on personal happiness.

Societies with a low IVR place emphasis on stricter social norms and more regulation of conduct and behavior. They are more pessimistic with a more rigid and controlled environment.

\subsection{Outcomes of Team Culture Composition}

There is a significant body of research that has examined the effects of cultural heterogeneity in teams and its effect on team performance. In summary, it is clear that a team's cultural composition has the potential to benefit or disrupt team performance $[15,23]$. However, the effect of homogenous versus heterogenous team cultures on team performance depends on the theoretical perspective taken and the context of the study. Therefore, to accurately explain all results, it is important to clearly define and theorize among team outcomes. We focus on two outcomes in particular that are most relevant to the software development team context: team performance and team member learning.

2.2.1. Team Performance. Generally speaking, research based on the similarity-attraction perspective [24] or social identity theory [25] finds that team cultural homogeneity is better for team performanceparticularly in the early stages of team formation [26]. Homogenous teams work together well because they have shared characteristics which are known to improve team cohesion and performance. In addition, cultural heterogeneity could provide biases that favor one culture's view of the task versus another's, resulting in a negative outcome [27]. Indeed, in their meta-analytic study, Horwitz and Horwitz [15] found that demographic similarity in teams did lead to improved performance.

On the other hand, studies based on cognitive diversity theory often find that heterogenous members promote improved creativity, innovation, and problem solving [28, 29] - all relevant outcomes indicative of performance in software development teams.

Finally, others have found that neither high nor low variance in team culture is favorable but that a moderate level of variance is optimal for team performance [22].

However, these seemingly mixed results may be explained by taking a long(er)-term view of team performance. In particular, one common explanation for the poor performance of multicultural teams is the lack of cross-cultural communication competence [30]. Differences in culture lead to poor communication which, in turn, leads to decreased performance [31]. Formal and informal communication is a critical success factor in software development [32]. Software projects often take many months to years to complete, which gives adequate time to make adjustments and improvements to communication styles. Indeed, media synchronicity theory indicates that communication styles and media evolve over time as team members 
become more familiar with one another and as a shared understanding of the task increases [33]. Therefore, it is also likely that short-term negative effects from cultural variance can and will be overcome over time such that the positive effects eventually outweigh the negatives. Therefore, we hypothesize:

\section{Hla: Team cultural variance negatively affects team performance in the short run \\ H1b: Team cultural variance positively affects team performance in the long run}

2.2.2. Team Member Learning. Although team performance is always a priority dependent variable in the short run, organizations realize that team members also need to grow and learn in order to maximize longterm performance [34, 35]. Learning is particularly important in software development teams where creativity and experience are primary factors for performance over time $[36,37]$. Therefore, we need to characterize a relevant definition of learning in software development teams to examine the effects of team personality.

Creativity has been identified as one of the most important characteristics of successful software developers and information systems (IS) practitioners [36-42] and, therefore, is a prime topic in academic IS curriculums [43, 44]. Management researchers have also argued that one's confidence in their ability to find creative solutions is as, or more, important as their actual creative abilities. This belief in one's ability to creatively solve unstructured problems is referred to as creative self-efficacy [35, 45, 46]. Most recently, IS researchers have adapted this construct to measure IS creative self-efficacy (CreaSE) which refers to, "...an individual's belief in their ability to develop creative solutions to new or unstructured business problems through the development of information systems that support business process and the people who execute them" [42, pg. 5].

Based on core theory on human creativity [47], CreaSE is a second-order formative construct with five independent factors [42]: 1) affect, 2) business skills, 3) intelligence, 4) people skills, and 5) technology training. Affect refers to our emotions, moods, and attitude [48] toward creative problem solving which has a significant effect on our creative performance. For example, negative affect can reduce our "flexible thinking" and problem-solving capabilities on complex tasks [49]. Business skills is a person's knowledge about the business domain they are working in including processes, strategies, and management. Intelligence is the factor that changes the least and refers to the cognitive ability for creativity a person is innately born with. People skills is a person's ability to collaborate effectively with others on a team and combine the good ideas from others into their own problem-solving framework. Finally, technology training refers to the hard technology skills that a person has, such as programming, data analytics, and computer systems, which will be combined and implemented in creative ways to solve IS problems.

CreaSE has been positioned as a primary outcome variable measuring the effectiveness of IS students and practitioners [42]. Therefore, we characterize a software development team member's learning as their improvement in CreaSE over time. Indeed, related research on work teams - although not in the IS context-has demonstrated that cohesive teams help team members use their CreaSE to actually produce creative results [45]. These experiences help to further develop an individual's CreaSE [42].

Because variability in team cultures may lead to conflict [50, 51] and lower team cohesion [52], we hypothesize:

H2: Team cultural variance negatively affects team member improvements in CreaSE.

\section{Methodology}

To test our hypotheses, we conducted a laboratory experiment with a class of 141 students enrolled in a Java-based software development course who were assigned team-based projects. A laboratory experiment was necessary in order to have the ability to manipulate team culture composition. To be clear, we do not mean that we manipulated individual cultures, but that we captured individual cultures with a pre-test and then randomly assigned them to groups of high cultural variance versus low cultural variance treatments. In other words, we implemented a 2-treatment, betweengroups design where teams were comprised of either homogenous or heterogeneous cultural composites. The exact procedures for this methodology are described next.

\subsection{Procedures}

At the beginning of the course, students were given a pre-survey measuring the 6-dimensional model of national culture (power distance, individualism vs collectivism, indulgence vs restraint, masculinity vs femininity, uncertainty avoidance, long- vs short-term orientation) based on Hofstede's Values Survey Model (VSM) 2013 instrument [4]. In addition, we measured a baseline score of their CreaSE using the validated instrument [42] so that their improvement in CreaSE (representing learning) could be calculated at the end of the course. 
As demonstrated in prior research on team personality composition [2], the next step would typically be to generate latent factor scores of the subconstructs. However, although the scale items used in the latest version of the VSM (2013) are intended to be measured at the individual level, they are not intended to be used to compare individuals as much as countries [4]. Individual level measures are to be averaged for a particular country and then used to compare two or more countries. As a result, the scale items do not exhibit (nor are they intended to) traditional measurement model criterion for reliability [53] or convergent and discriminant validity $[54,55]^{1}$. Therefore, it would be inappropriate to generate latent factor scores based on the six dimensions of national culture.

This does not mean that the scale cannot be used by a sample that is dominated by a single national culture such as ours. In these cases, Hofstede [4] recommends calculating an average score across the four items measuring each dimension as well as a sample size greater than 50 .

Furthermore, by using the individual level measures for our analysis, the results represent the individual's cultural personality [56] as opposed to a country-level culture. This is desirable for our research context because it makes our results more comparable to prior research on software team personality composition $[2$, 57].

In summary, because latent factor scores should not be generated for the six dimensions of culture, we used an average of the four scale items measuring each of the six dimensions to perform a cluster analysis to segment the individuals into unique cultures. The clustering algorithm used was k-means. A gap statistic [58] was calculated for every combination of clusters from 2 to 25 which determined that the data best fit into only two clusters. We then recorded the Euclidean distance for each participant representing the closeness of their score across all five traits to the center of the nearest of the two clusters. This allowed us to characterize team members' overall culture across all six dimensions as well as how closely they fit within that cultural cluster. Figure 2 illustrates the actual average personality trait scores between the two clusters.

${ }^{1}$ This is not to say that the scale does not exhibit sufficient measurement model properties. However, the analyses must take place at the country level rather than the individual level. Because we use the scale for predominantly one country, and

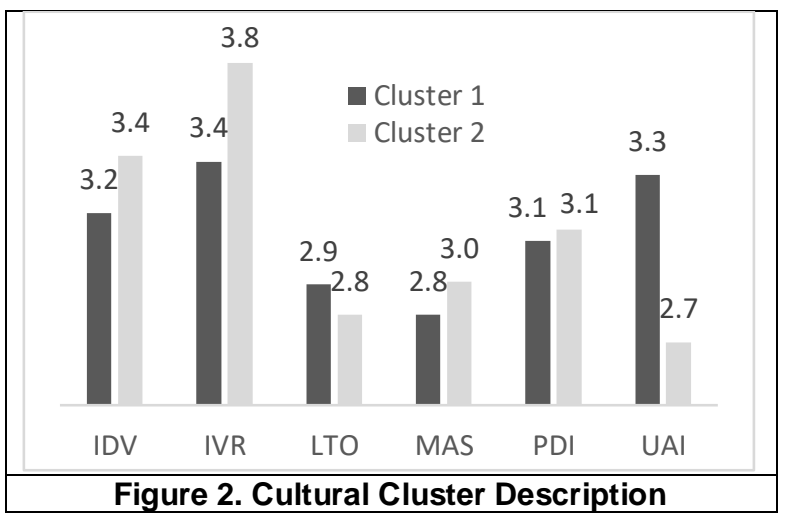

Analysis of variance (ANOVA) tests reveal that IDV $(F=17.19, \mathrm{p}<0.001)$, IVR $(F=46.48, \mathrm{p}<0.001)$, LTO $(F=3.91, \mathrm{p}=0.050)$, and UAI $(F=173.65, \mathrm{p}<0.001)$ each significantly differentiated the two clusters. MAS was marginally significant $(F=3.356, \mathrm{p}=0.069)$ while PDI did not differentiate between the clusters $(F=0.37$, $\mathrm{p}=0.545)$. In summary, a person in Cluster $1(\mathrm{n}=65)$ represents those who are more collectivistic, restrained, long-term oriented, risk-avoiding, and marginally feminine. We label Cluster 1 as "moderate team players." Cluster $2(\mathrm{n}=76)$ represents those who are more individualistic, indulgent, short-term oriented, risk-seeking, and marginally masculine. We label Cluster 2 as the "aggressive individuals."

3.3.1. Manipulation. Once every participant had been classified into a cultural cluster, we manipulated the variability of team personality composition by randomly assigning (with stratification into equal sized teams) them into teams of four that were comprised of individuals of either a) the same cultural cluster, or b) two from each cultural cluster. In other words, they were randomly assigned to either homogeneous (based on culture) teams or heterogeneous teams. However, because there was not an even number of participants in each cultural cluster, we had to keep the number of participants equal in the heterogeneous treatment to balance the teams (two members of each culture type) while having different numbers of homogenous teams (see Table 1).

\begin{tabular}{|l|c|c|c|}
\hline \multicolumn{4}{|c|}{ Table 1. Number of Participants } \\
\hline & $\begin{array}{c}\text { Cluster 1 } \\
\text { "moderate } \\
\text { team } \\
\text { players" }\end{array}$ & $\begin{array}{c}\text { Cluster 2 } \\
\text { individuals" }\end{array}$ & Teams \\
\hline Homogeneous & 32 & 41 & 21 combined \\
\hline
\end{tabular}

because the scale has been repeatedly refined and validated across hundreds of countries [3], we adopt it for this study in the exact form recommended by Hofstede [4] without reanalyzing the measurement properties at the country level. 


\begin{tabular}{|l|l|l|l|}
\hline Heterogeneous & 33 & 35 & 18 combined \\
\hline
\end{tabular}

At the end of the semester, we collected students' effectiveness data, which was their grades from three team-based projects during the semester. All students participated in the same assignments under the same professor, with the same resources available to them. We also administered another survey to collect the CreaSE instrument again to measure learning and improvement in their confidence in writing code to solve business problems.

\section{Results}

Figure 3 depicts the learning that took place over the semester represented as the improvement in the overall CreaSE score. When using overall CreaSE, there is no difference in learning improvement. However, Figure 3 shows only the improvement in the technology training (TRA) sub-construct of CreaSE which is where the primary difference occurred. Heterogeneous teams appeared to improve their confidence in their technology skills at only a slightly greater rate than homogenous teams.

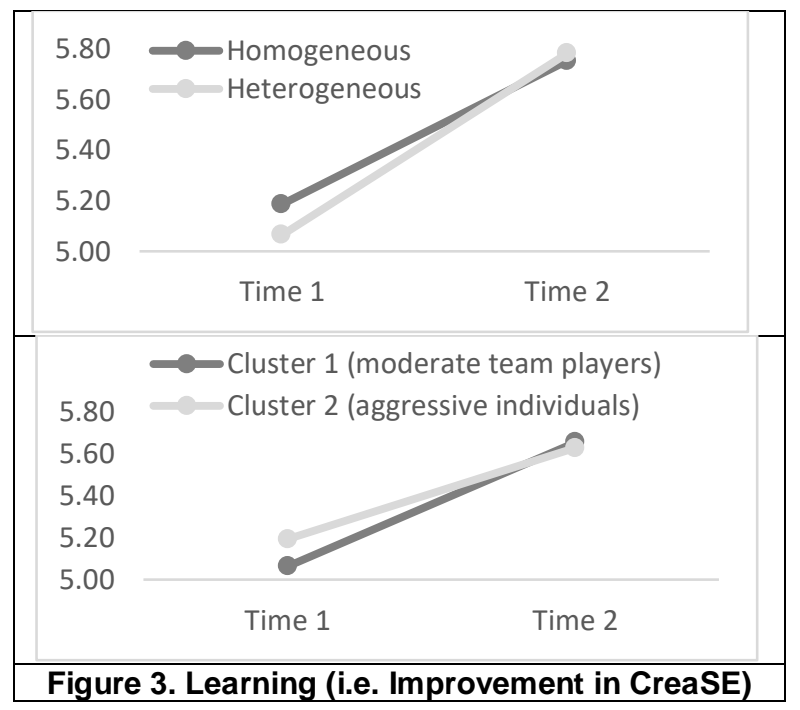

Figure 4 depicts the three team-based projects used to calculate their team effectiveness score. The projects are listed in the chronological order they were delivered in. These images suggest the following: 1) the "aggressive individuals" (who also rated lower in longterm orientation) start off with great performance, but they drop below the "moderate team players" over time, and 2) teams with heterogenous cultures start off with lower performance but outperform those with homogeneous cultures over time.

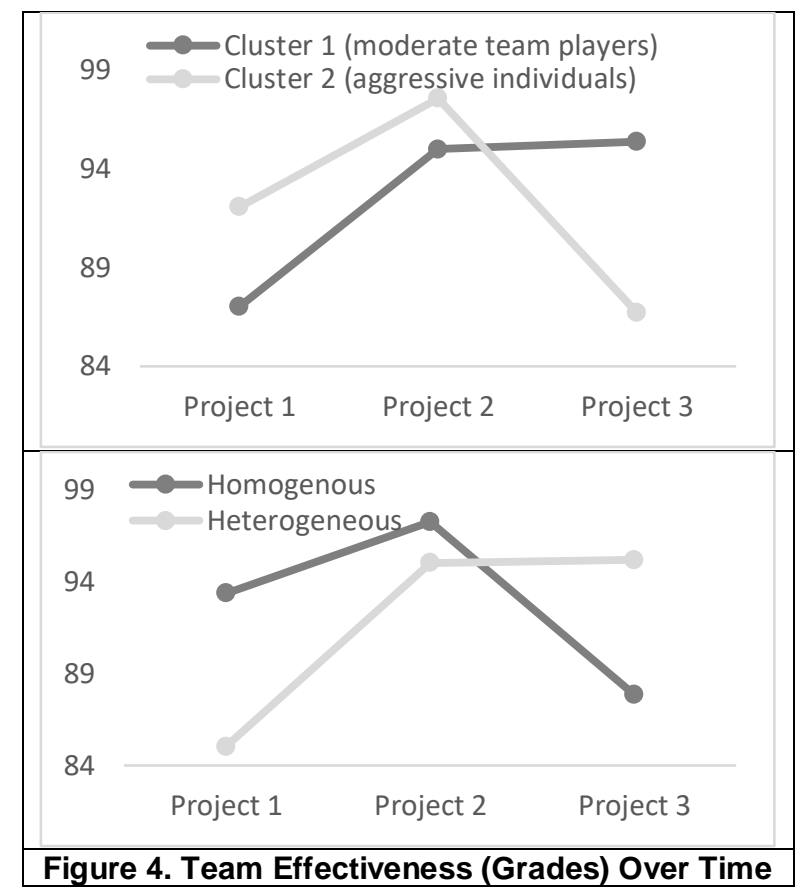

Table 2 summarizes the results of a multivariate ANOVA using the treatment and the cluster as factors with the Euclidean distance from the cluster and age as covariates. To better understand the results, we broke apart the CreaSE scale into the sub constructs (as is common [e.g., 52, 59]). For simplicity, we include the only significant effects of Cluster, all effects of Treatment, and only the marginally significant and significant effects of the interaction between Cluster and Treatment. The CreaSE scores used in this analysis are based on averages of the items representing each construct. Although we manipulated cultural composition at the team level, we analyze the MANOVA at the individual level because learning (CreaSE) is an individual construct. Analyzing team effects on individual constructs is common in studies of teams and learning $[60,61]$.

\begin{tabular}{|l|l|r|r|r|}
\hline \multicolumn{5}{|c|}{ Table 2. Multivariate ANOVA Results } \\
\hline Factor & \multicolumn{1}{|c|}{ DV } & Mean square & F & p-value \\
\hline Cluster & Project 3 & 2687.30 & 4.895 & 0.029 \\
\hline Treatment & CreaSE_AFF & 0.040 & 0.156 & 0.693 \\
\cline { 2 - 5 } & CreaSE_BUS & 0.141 & 0.174 & 0.677 \\
\cline { 2 - 5 } & CreaSE_INT & 0.188 & 0.960 & 0.329 \\
\cline { 2 - 5 } & CreaSE_PEO & 0.040 & 0.054 & 0.816 \\
\cline { 2 - 5 } & CreaSE_TRA & 0.015 & 0.017 & 0.896 \\
\cline { 2 - 5 } & Project 1 & 2435.574 & 3.625 & 0.059 \\
\cline { 2 - 5 } & Project 2 & 236.278 & 0.827 & 0.365 \\
\cline { 2 - 5 } & Project 3 & 2048.823 & 4.129 & 0.044 \\
\hline Cluster x & Project 1 & 2777.190 & 4.133 & 0.044 \\
\cline { 2 - 5 } Treatment & Project 3 & 2539.071 & 5.118 & 0.025 \\
\cline { 2 - 5 } & CreaSE_AFF & 0.712 & 3.615 & 0.059 \\
\hline
\end{tabular}

In summary, those in Cluster 1 (moderate team 
players) scored significantly better on Project 3 . Interestingly, there was no effect of the treatment on learning. Thus, H2 was not confirmed. However, homogeneous groups scored marginally better on Project 1 while heterogeneous groups scored significantly better over time on Project 3-thus, confirming H1a and H1b.

To explore this effect in more detail, we analyzed a post-hoc interaction effect between Cluster and Treatment and found several marginal and significant effects. Figure 5 helps to explain these effects. In particular, those in Cluster 1 (aggressive individuals) performed significantly worse over time when they were placed in homogenous teams whereas Cluster 2 performed the same over time regardless of their team cultural homogeneity.

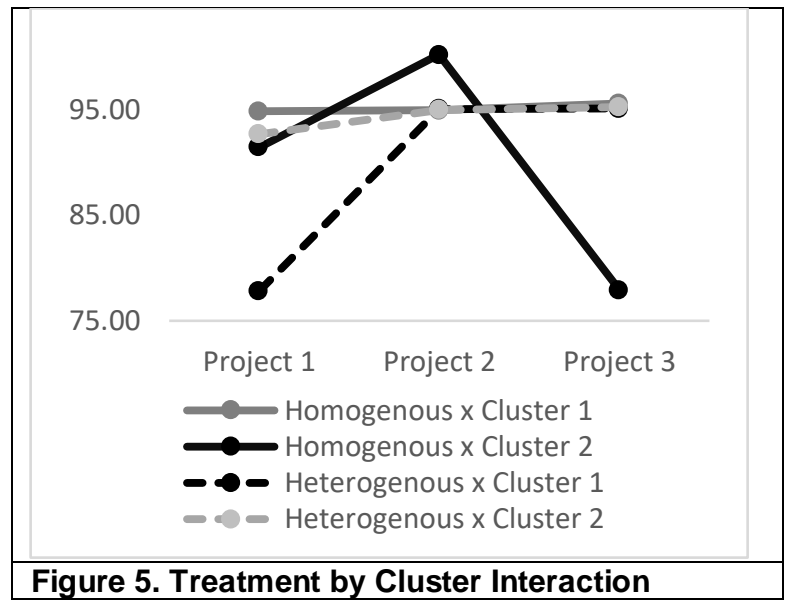

\section{Discussion}

In summary, teams comprised of homogeneous cultures exhibit greater performance initially. However, in the long run, teams with heterogenous cultures perform best.

Combined with the results of prior research [2] on the "Big 5" model of personality traits [62], Figure 6 visualizes the combined effects of team personality and cultural composition. In summary, personality (measured as the Big 5 traits) affects learning through improvements in CreaSE while culture affects team performance.

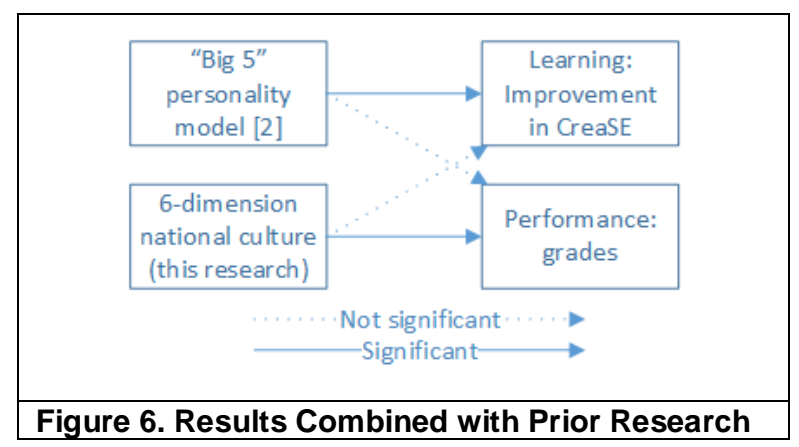

\subsection{Implications, Limitations, and Future Research}

The primary implication of this line of research is that software development teams can be positively affected by 1) measuring individual culture 2) segmenting individuals into heterogenous clusters, and 3) placing them in teams of homogenous composition for short-term tasks, but heterogeneous composition for long-term tasks.

Interestingly, we also found evidence of an interaction between our treatment and the cluster that the team member belonged to. In particular, those with cultural values that were high in individualism, indulgence, short-term orientation, and risk-seeking (i.e. the "aggressive individuals") performed significantly worse over time if they were in a group with similar cultural values. However, those same types of individuals converged around the same level of performance as other cultural types if they were placed in a group with diverse cultures. The implication is that individuals of this cultural/personality type should not be grouped together in a homogenous group in practice.

Although this study did not find a significant effect of team culture heterogeneity on learning (improvement in CreaSE), we do not believe this finding is conclusive. Because CreaSE was measured only at the beginning and end of the period, we do not know if there were differential effects - similar to the performance scores. For example, it is possible that homogenous teams had a greater CreaSE improvement in the short term while heterogeneous teams had a greater improvement in the long term. Future research should address this with more regular measurements of CreaSE.

Another limitation of this research was that the experiment was conducted on a small dataset of students comprised of just 39 teams made up of 141 students. Naturally, our effects may be different in real software development organizations. Similarly, our students were primarily male and Caucasian and represented a very homogenous cultural sample to begin with. However, this limitation actually plays in favor of our 
results because our methodology depends on segmenting team members into clusters that are as different as possible. Therefore, the fact that we found a significant treatment effect with relatively similar clusters suggests that even greater effects may be found with samples of relatively more heterogenous groups of potential team members.

Despite our use of student teams, our implications are also still very significant for IS academic programs that are motivated to maximize students' learning. IS programs should also measure personalities and optimize teams for improvements in CreaSE. However, a clear opportunity for future research is to replicate our study in a real business environment which would produce more confidence for managers in the results.

Another limitation/opportunity is that the students in our experiment were programming novices. For most, this course was the first course in software development. Therefore, our results may be quite different for intermediate to advanced developers who already have a cognitive basis for programming knowledge and may be more able to cope with, and take advantage of, differing cultures. Therefore, future research should certainly replicate our results with more advanced programming teams.

Another idea for future research is to focus on defining the combination of diverse cultures to achieve the highest level of software development performance and the combination of cultural values and beliefs to achieve the highest level of software development learning. This could allow organizations to maximize their possibility to achieve their desired outcome of learning or performance.

Another limitation of our research is that we identified only two types of cultural clusters. This result was favorable for an initial experiment like ours. However, with greater participation, future research should identify more clusters of cultures and estimate their effects on various roles in a software development team (e.g. design, code, test).

Finally, it should be noted that our experimental design-although motivated by the software development context-may be applicable to a wide variety of engineering teams and other teams that depend on learning over time. Future research should measure additional variables that are more specific to individual domains.

\section{Conclusion}

In conclusion, managers and academic departments using team-based software development would benefit from measuring personalities and combining similar cultures to maximize effectiveness and learning-at least in the early stages of a student's program or employee's career.

\section{References}

[1] Keith, M., Demirkan, H., and Goul, M., "Service-Oriented Methodology for Systems Development", Journal of Management Information Systems, 30(1), 2013, pp. 227-260. [2] Anderson, G., Keith, M.J., Francisco, J., and Fox, S., "The Effect of Software Team Personality Composition on Learning and Performance: Making the" Dream" Team", in (Editor, 'ed.'^'eds.'): Book The Effect of Software Team Personality Composition on Learning and Performance: Making the" Dream" Team, Hawaii, USA, 2018

[3] Hofstede, G.H., and Minkov, G., Cultures and Organizations: Software of the Mind, 2010.

[4] Hofstede, G., Hofstede, G.J., Minkov, M., and Vinken, H., "Values Survey Module 2013", URL: http://www. geerthofstede. nl/vsm2013, 2013,

[5] Winsborough, D., and Chamorro-Premuzic, T., "Great Teams Are About Personalities, Not Just Skills", in (Editor, 'ed.'^'eds.'): Book Great Teams Are About Personalities, Not Just Skills, 2017

[6] Cataldo, M., and Herbsleb, J.D., "Coordination Breakdowns and Their Impact on Development Productivity and Software Failures", IEEE Transactions on Software Engineering, 39(3), 2013, pp. 343-360.

[7] Schmidt, R., Lyytinen, K., Keil, M., and Cule, P., "Identifying Software Project Risks: An International Delphi Study", Journal of Management Information Systems, 17(4), 2001, pp. 5-36.

[8] Thomas-Hunt, M.C., Ogden, T.Y., and Neale, M.A., "Who's Really Sharing? Effects of Social and Expert Status on Knowledge Exchange within Groups", Management Science, 49(4), 2003, pp. 464-477.

[9] Dahlin, K.B., Weingart, L.R., and Hinds, P.J., "Team Diversity and Information Use", Academy of Management Journal, 48(6), 2005, pp. 1107-1123.

[10] Peeters, M.A., Van Tuijl, H.F., Rutte, C.G., and Reymen, I.M., "Personality and Team Performance: A Meta-Analysis", European Journal of Personality, 20(5), 2006, pp. 377-396.

[11] Fazli, F., and Bittner, E.a.C., "Cultural Influences on Collaborative Work in Software Engineering Teams", in (Editor, 'ed.'^'eds.'): Book Cultural Influences on Collaborative Work in Software Engineering Teams, 2017

[12] Nowak, M.A., and Sigmund, K., "Evolution of Indirect Reciprocity by Image Scoring", Nature, 393(6685), 1998, pp. 573.

[13] Sie, R.L., Bitter-Rijpkema, M., Stoyanov, S., and Sloep, P.B., "Factors That Influence Cooperation in Networks for Innovation and Learning", Computers in Human Behavior, 37(2014, pp. 377-384.

[14] Lukinova, E., Babkina, T., and Myagkov, M., "Choosing Your Teammates Creates Social Identity and Keeps Cooperation Rates High", World Academy of Science, Engineering and Technology International Journal of Economics and Management Engineering, 7(2015,

[15] Horwitz, S.K., and Horwitz, I.B., "The Effects of Team Diversity on Team Outcomes: A Meta-Analytic Review of Team Demography", Journal of Management, 33(6), 2007, pp. 987-1015. 
[16] Chatman, J.A., and Flynn, F.J., "The Influence of Demographic Heterogeneity on the Emergence and Consequences of Cooperative Norms in Work Teams", Academy of Management Journal, 44(5), 2001, pp. 956-974.

[17] Maznevski, M.L., and Chudoba, K.M., "Bridging Space over Time: Global Virtual Team Dynamics and Effectiveness", Organization Science, 11(5), 2000, pp. 473492.

[18] Gibbs, J.L., Sivunen, A., and Boyraz, M., "Investigating the Impacts of Team Type and Design on Virtual Team Processes", Human Resource Management Review, 27(4), 2017, pp. 590-603.

[19] Gorgone, J., Davis, G.B., Valacich, J.S., Topi, H., Feinstein, D.L., and Longenecker, H.E., "Is 2002 Model Curriculum and Guidelines for Undergraduate Degree Programs in Information Systems", Communications of the Association for Information Systems, 11(1), 2003, pp. 1.

[20] Barsade, S.G., Ward, A.J., Turner, J.D., and Sonnenfeld, J.A., "To Your Heart's Content: A Model of Affective Diversity in Top Management Teams", Administrative science quarterly, 45(4), 2000, pp. 802-836.

[21] Hofstede, G., Culture's Consequences: Comparing Values, Behaviors, Institutions and Organizations across Nations, Sage publications, 2003.

[22] Cheng, C.Y., Chua, R.Y., Morris, M.W., and Lee, L., "Finding the Right Mix: How the Composition of SelfManaging Multicultural Teams' Cultural Value Orientation Influences Performance over Time", Journal of Organizational Behavior, 33(3), 2012, pp. 389-411.

[23] Van Knippenberg, D., and Schippers, M.C., "Work Group Diversity", Annu. Rev. Psychol., 58(2007, pp. 515-541.

[24] Byrne, D.E., The Attraction Paradigm, Academic Pr, 1971.

[25] Tajfel, H., and Turner, J.C., "The Social Identity Theory of Intergroup Behavior", 2004,

[26] Earley, C.P., and Mosakowski, E., "Creating Hybrid Team Cultures: An Empirical Test of Transnational Team Functioning", Academy of Management Journal, 43(1), 2000, pp. 26-49.

[27] Stahl, G.K., Maznevski, M.L., Voigt, A., and Jonsen, K., "Unraveling the Effects of Cultural Diversity in Teams: A Meta-Analysis of Research on Multicultural Work Groups", Journal of international business studies, 41(4), 2010, pp. 690709.

[28] Cox, T.H., and Blake, S., "Managing Cultural Diversity: Implications for Organizational Competitiveness", The Executive, 1991, pp. 45-56.

[29] Hambrick, D.C., Cho, T.S., and Chen, M.-J., "The Influence of Top Management Team Heterogeneity on Firms' Competitive Moves", Administrative science quarterly, 1996, pp. 659-684.

[30] Matveev, A.V., and Nelson, P.E., "Cross Cultural Communication Competence and Multicultural Team Performance: Perceptions of American and Russian Managers", International Journal of Cross Cultural Management, 4(2), 2004, pp. 253-270.

[31] Shachaf, P., "Cultural Diversity and Information and Communication Technology Impacts on Global Virtual Teams: An Exploratory Study", Information \& Management, 45(2), 2008, pp. 131-142.
[32] Keith, M., Demirkan, H., and Goul, M., "The Role of Task Uncertainty in It Project Team Advice Networks", Decision Sciences, 48(2), 2017, pp. 207-247.

[33] Dennis, A.R., Fuller, R.M., and Valacich, J.S., "Media, Tasks, and Communication Processes: A Theory of Media Synchronicity", Mis Quarterly, 32(3), 2008, pp. 575-600.

[34] Hirst, G., Van Knippenberg, D., and Zhou, J., "A CrossLevel Perspective on Employee Creativity: Goal Orientation, Team Learning Behavior, and Individual Creativity", Academy of Management Journal, 52(2), 2009, pp. 280-293. [35] Gong, Y., Huang, J.-C., and Farh, J.-L., "Employee Learning Orientation, Transformational Leadership, and Employee Creativity: The Mediating Role of Employee Creative Self-Efficacy", Academy of Management Journal, 52(4), 2009, pp. 765-778.

[36] Beck, K., Beedle, M., Van Bennekum, A., Cockburn, A., Cunningham, W., Fowler, M., Grenning, J., Highsmith, J., Hunt, A., and Jeffries, R., "Manifesto for Agile Software Development", 2001,

[37] Mcleod, L., and Macdonell, S.G., "Factors That Affect Software Systems Development Project Outcomes: A Survey of Research", ACM Computing Surveys (CSUR), 43(4), 2011, pp. 24.

[38] Gu, M., and Tong, X., "Towards Hypotheses on Creativity in Software Development", in (Editor, 'ed.'^'eds.'): Book Towards Hypotheses on Creativity in Software Development, Springer, 2004, pp. 47-61.

[39] Highsmith, J., and Cockburn, A., "Agile Software Development: The Business of Innovation", Computer, 34(9), 2001, pp. 120-122.

[40] Tiwana, A., and Mclean, E.R., "Expertise Integration and Creativity in Information Systems Development", Journal of Management Information Systems, 22(1), 2005, pp. 13-43.

[41] Nunamaker Jr, J.F., Applegate, L.M., and Konsynski, B.R., "Facilitating Group Creativity: Experience with a Group Decision Support System", Journal of Management Information Systems, 3(4), 1987, pp. 5-19.

[42] Payne, K., Keith, M.J., Babb, J.S., and Spruill, A., "Development and Validation of the Information Systems Creative Self-Efficacy Scale", in (Editor, 'ed.'^'eds.'): Book Development and Validation of the Information Systems Creative Self-Efficacy Scale, Waikaloa, HI, 2018

[43] Hirschheim, R., and Klein, H.K., "A Glorious and NotSo-Short History of the Information Systems Field", Journal of the Association for Information Systems, 13(4), 2012, pp. 188.

[44] Hirschheim, R., Saunders, C., and Straub, D., "Historical Interpretations of the Is Discipline: An Introduction to the Special Issue", Journal of the Association for Information Systems, 13(4), 2012, pp. 1-8.

[45] Richter, A.W., Hirst, G., Van Knippenberg, D., and Baer, M., "Creative Self-Efficacy and Individual Creativity in Team Contexts: Cross-Level Interactions with Team Informational Resources", Journal of Applied Psychology, 97(6), 2012, pp. 1282.

[46] Tierney, P., and Farmer, S.M., "Creative Self-Efficacy: Its Potential Antecedents and Relationship to Creative Performance", Academy of Management Journal, 45(6), 2002, pp. 1137-1148.

[47] Hennessey, B.A., and Amabile, T.M., "Creativity", Annual review of psychology, 61(2010, pp. 569-598. 
[48] Blanchette, I., and Richards, A., "The Influence of Affect on Higher Level Cognition: A Review of Research on Interpretation, Judgement, Decision Making and Reasoning", Cognition \& Emotion, 24(4), 2010, pp. 561-595.

[49] Aspinwall, L.G., "Rethinking the Role of Positive Affect in Self-Regulation", Motivation and Emotion, 22(1), 1998, pp. $1-32$.

[50] Schneewind, K.A., and Gerhard, A.K., "Relationship Personality, Conflict Resolution, and Marital Satisfaction in the First 5 Years of Marriage", Family Relations, 51(1), 2002, pp. 63-71.

[51] Liang, T.-P., Liu, C.-C., Lin, T.-M., and Lin, B., "Effect of Team Diversity on Software Project Performance", Industrial Management \& Data Systems, 107(5), 2007, pp. 636-653.

[52] Van Vianen, A.E., and De Dreu, C.K., "Personality in Teams: Its Relationship to Social Cohesion, Task Cohesion, and Team Performance", European Journal of Work and Organizational Psychology, 10(2), 2001, pp. 97-120.

[53] Santos, J.R.A., "Cronbach's Alpha: A Tool for Assessing the Reliability of Scales", Journal of extension, 37(2), 1999, pp. 1-5.

[54] Fornell, C., and Bookstein, F.L., "Two Structural Equation Models: Lisrel and Pls Applied to Consumer ExitVoice Theory", Journal of Marketing Research, 19(4), 1982, pp. 440-452.

[55] Fornell, C., and Larcker, D.F., "Evaluating Structural Equation Models with Unobservable Variables and Measurement Error", Journal of Marketing Research, 18(1981), 1981, pp. 39-50.
[56] Hofstede, G., and Mccrae, R.R., "Personality and Culture Revisited: Linking Traits and Dimensions of Culture", Crosscultural research, 38(1), 2004, pp. 52-88.

[57] Halfhill, T., Sundstrom, E., Lahner, J., Calderone, W., and Nielsen, T.M., "Group Personality Composition and Group Effectiveness: An Integrative Review of Empirical Research", Small group research, 36(1), 2005, pp. 83-105.

[58] Tibshirani, R., Walther, G., and Hastie, T., "Estimating the Number of Clusters in a Data Set Via the Gap Statistic", Journal of the Royal Statistical Society: Series B (Statistical Methodology), 63(2), 2001, pp. 411-423.

[59] Beal, D.J., Cohen, R.R., Burke, M.J., and Mclendon, C.L., "Cohesion and Performance in Groups: A Meta-Analytic Clarification of Construct Relations", Journal of Applied Psychology, 88(6), 2003, pp. 989-1004.

[60] O'leary, M.B., Mortensen, M., and Woolley, A.W., "Multiple Team Membership: A Theoretical Model of Its Effects on Productivity and Learning for Individuals and Teams", Academy of Management Review, 36(3), 2011, pp. 461-478.

[61] Hoegl, M., Parboteeah, K.P., and Munson, C.L., "TeamLevel Antecedents of Individuals' Knowledge Networks", Decision Sciences, 34(4), 2003, pp. 741-770.

[62] Goldberg, L.R., Johnson, J.A., Eber, H.W., Hogan, R., Ashton, M.C., Cloninger, C.R., and Gough, H.G., "The International Personality Item Pool and the Future of PublicDomain Personality Measures", Journal of Research in Personality, 40(1), 2006, pp. 84-96. 